\title{
The Feasibility Analysis and Scheme Design of Raw Milk Price Index Insurance in China
}

\author{
Liyu Feng \\ School of Insurance \\ Central University of Finance and Economics, Beijing, China
}

\begin{abstract}
Dairy producers in China has been suffering from more and more frequently raw milk price fluctuations in recent years. Price Index insurance can be an effective tool of market risk management. We find that there are foreseeable trend, cyclical and seasonal factors in raw milk price fluctuations, and also systematicness in price risk, which make the raw milk price risk uninsurable. But by rationally designing the insurance scheme and institutional innovations, the price risks could become insurable. The choice and construction of milk price index are the core tasks of the scheme design. Income over feed cost could well reflect the actual profitability of milk production and is good to be used as milk price index. To prevent moral hazards and adverse selection, the contract should make stipulations on the coverage level from aspects of production covered and risk retention. We also carry a calculation of actuarially fair premium for the designed insurance contract using distribution approximation and Monte Carlo stimulation.
\end{abstract}

Keywords: Raw milk, Price index insurance, Feasibility, Insurance scheme

\section{INTRODUCTION}

Agricultural insurance programs have been developing steadily under the supporting policies of government in China since 2007. And they play important roles in protecting agricultural production, stabilizing farmers' income and guaranteeing the national food security. In 2016, the total gross premium of agricultural insurance in China increased to 41.77 billion RMB by $11.42 \%$ from 2015 and achieved a 0.1 percentage point growth of its proportion in non-life insurance sector with $4.79 \%$. The government fund for agricultural insurance premium subsidies in 2016 was 15.83 billion RMB, which increased by 7.47\% from 2015. 204 million farmer households were covered by the insurance programs with a total insurance amount of 2.16 trillion RMB.

The existing products are mainly designed to cover the loss risks caused by natural disasters, plants' or animals' diseases and accidents. There's still a lack of protection for market risk, such as price risks and margin risks in agricultural production and operation. In 2011, Shanghai government and Anxin Agricultural Insurance Company took the lead in conducting a vegetable price index insurance plot, which received widely attention and favorable comments. Beijing government and Anhua Agricultural Insurance Company set up swine price index insurance plot in 2013. In 2014, the central government No.1 document proposed to explore carrying out crops and livestock price insurance plots. Since then, many provinces began to conduct price insurance programs on farm produce like swine and vegetable one after another, which showed a rapid development trend.

Dairy products have become important side dishes for Chinese homes in recent years. China's milk productivity ranks 3rd in the world, and the increasing dairy consumption is promoting the unceasing growth of the number of dairy cows. But for the lack of available market risk management tools, the price of raw milk went through several great fluctuations in the past 
few years, which resulted in the alternate phenomenon of "low price hurts famers" and "high price hurts consumers". The market risks dairy producers faced have become far higher than the natural risks. Most of the dairy cattle herds in China are in small scale with cows less than 100. It's not convenient for them to use futures or options market which have relative high thresholds to hedge risks. Actually, there are still no dairy milk future and related option products now in China yet. Meanwhile, compared with the government behaviors of direct agricultural products purchasing and subsidies, insurance tools have higher efficiency in maintaining the market order and the self-adjust of commodity prices. Therefore the best choice for spreading the market risks in dairy milk production is to design and carry out insurance programs for milk price. Take "index" instead of the actual price received by dairy producers as basis of measuring losses can effectively decrease the transaction cost of insurance contracts and avoid moral hazards and adverse selection.

\section{LITERATURE REVIEW}

History of insuring agricultural products price risks is not long in the world. So the researches about risk management of agricultural products prices, especially of milk price are still limited in number.

Chuhui Liao(2012) did a case study about the cost based vegetable price insurance program operated by Shanghai Anxin Agricultural Insurance Company, and concluded that the insurance project could effectively stabilize vegetable supply and didn't cause welfare dissipation because of the appropriate insured amount control [4]. Qiao Zhang(2013) designed a scheme of eggs price insurance for Beijing after analyzing the fluctuation patterns of eggs price and egg-to-feed price ratio. But the feasibility analysis of this scheme was not referred and it's also difficult to put into practice [13]. Ke Wang(2014) regarded adverse selection as the core problem of swine price insurance development based on investigation of foreign experiences. He also suggested that the scheme design should comply with the needs of actual production and spread the underwriting risks as far as possible [9]. And it's quite important to improve the market price monitor system. Qiao Zhang(2015) found that though price risks had systematic and partly expectable characteristics, they could be turned into insurable risks by technical and institutional innovations [12]. He also put forward the key points of designing swine price insurance program in China. Later in 2016, Qiao Zhang pointed that the two key problems in large-scale application of agricultural products price insurance were setting up the insurance indicator and trigger value and catastrophic risks. The future markets could effectively solve these problems considering their price discovery and risk transfer function. Starting from talking about the necessity and development situation, Hui Tian (2016) analyzed the main difficulties and principles of developing agricultural products price insurance in China [8]. Guodong and Ke (2016) introduced the concept of agricultural products price insurance and proposed design framework for this kind of insurance products taking raw milk margin protection insurance as example [7].

In recent years, many foreign scholars have studied on the field of livestock products market risk management, including dairy milk, from several aspects. Cabrera and Solis (2008) evaluated the effectivity of weather forecasts in managing "Livestock Gross Margin- Dairy" (LGM-D) using data of dairy herds in Wisconsin [2]. Cabrera (2009) discussed the relationships between the factors like feed quantity insured and premiums or the guaranteed gross margin, and found strong negative correlations between deductibles and premium, corn insured and guaranteed gross margin [3]. M.Valvekar (2010) recommended dairy producers who had enrolled in LGM-D making purchasing plans to save premium cost [18]. C.A.Wolf (2010) examined the using of milk-to-feed price ratio as proxy for dairy farm profitability, and 
concluded that income over feed cost (IOFC) could be a better profitability indicator when both milk price and feed costs in high volatility [20]. His another research (2012) proved that more and more dairy producers were managing both milk and feed price risks simultaneously [21]. Operations with larger scales, more shareholders and younger managers generally had higher enthusiasm in risk management. Marin (2014) investigated dairy producers' understanding, attitudes, impression and participation willingness towards Margin Protection Program (MPP) [1]. Tyler and Kenneth (2015) evaluated the efficiency of MPP in increasing producers' income and decreasing risks using data of 13 dairy production areas from 2002-2013, and concluded that this program was indeed helpful and effective after comparing it with LGM [10].

The existing researches verified the positive significance of price insurance in lowering market risks faced by agricultural producers in production and operation, and also provide good references for our scheme design of raw milk price index insurance that suitable to Chinese reality.

\section{FEASIBILITY OF RAW MILK PRICE INDEX INSURANCE}

\section{Fluctuation Characteristics of Raw Milk Price}

Influenced by the "Sanlu" incident, the raw milk price kept going down in a short period after that and began to slowly revive until the second half of 2009. After a relatively long period of steadily increase, the raw milk price sharply fell again in 2014. The main reason for this was that the government introduced more preferential import policy for foreign dairy products, which led to a flood of foreign milk into domestic market and strongly struck the home produces.

To clearly understand the historical fluctuation characteristics of raw milk price in China market, we do seasonal adjustments and decomposition of the price series with X-12 seasonal adjustment method and Hodrick-Prescott filter. We find there were trend and cyclical factors, seasonal factors and irregular factors in the raw milk price fluctuation.

\section{Trend and cyclical factors}

Figure 1 shows that the raw milk price was in an increase trend for a long period during the past 10 years, but turned around and kept descending from 2014. After removing the long term trend from trend and cycle series, we get the cycle moving series of raw milk price. With the "peak to peak" cycle partition method, we can divide the period from July, 2008 to September, 2017 into three fluctuation periods. The length of the first period is 33 months from July, 2008 to April, 2011. The second is 34 months from May, 2011 to March, 2014. And the last is not ended yet and has been 39 months long from April, 2014. The lengths of these 3 period are all about 3 years. From the view of moving path, the downward phase of raw milk price of the first and third cycle both continued for 13 months, during which the price decreased sharply. Comparatively, the second cycle was steadier, and the decreasing period was longer. Meanwhile, we can see that the raw milk price didn't pick up rapidly after the steep decline in the last cycle as the former cycles did. The possible explanation is that, affected by price collapse of global milk price, the processing operations preferred to use imported raw milk which has higher cost-performance. The oversupply of domestic milk resulted in the below-cost price. Although the government has taken a series of emergency measures, the impacts of low cost foreign raw milk would be still there in the foreseeable future. 


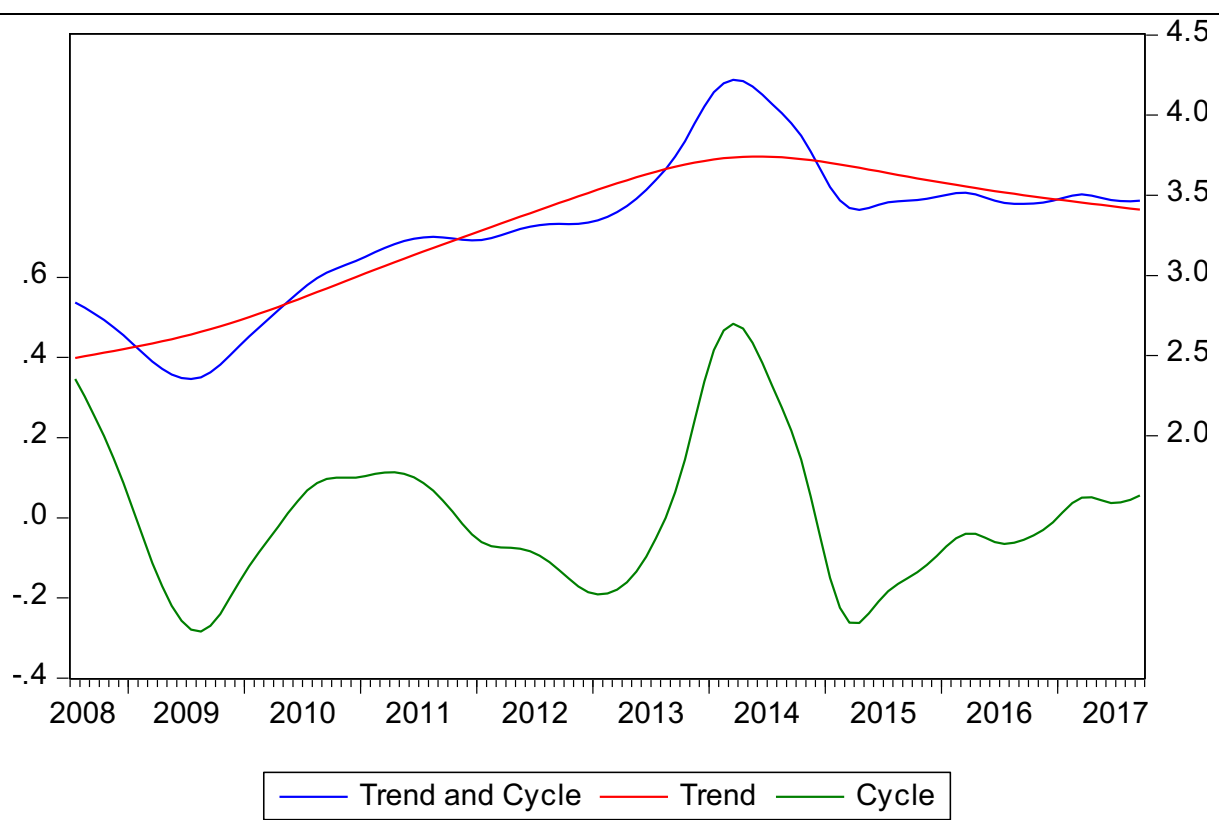

Figure 1. Trend and Cyclical Fluctuation of National Average Price of Raw Milk (monthly)

\section{Seasonal factors}

Figure2 illustrates the regularly seasonal fluctuations of raw milk price in China. The peak were all in January in every year, and valley in August. From every September, the price began to recover and reached the top point in the next January. From the view of fluctuation amplitude, the influence of seasonal factors has been getting slighter.

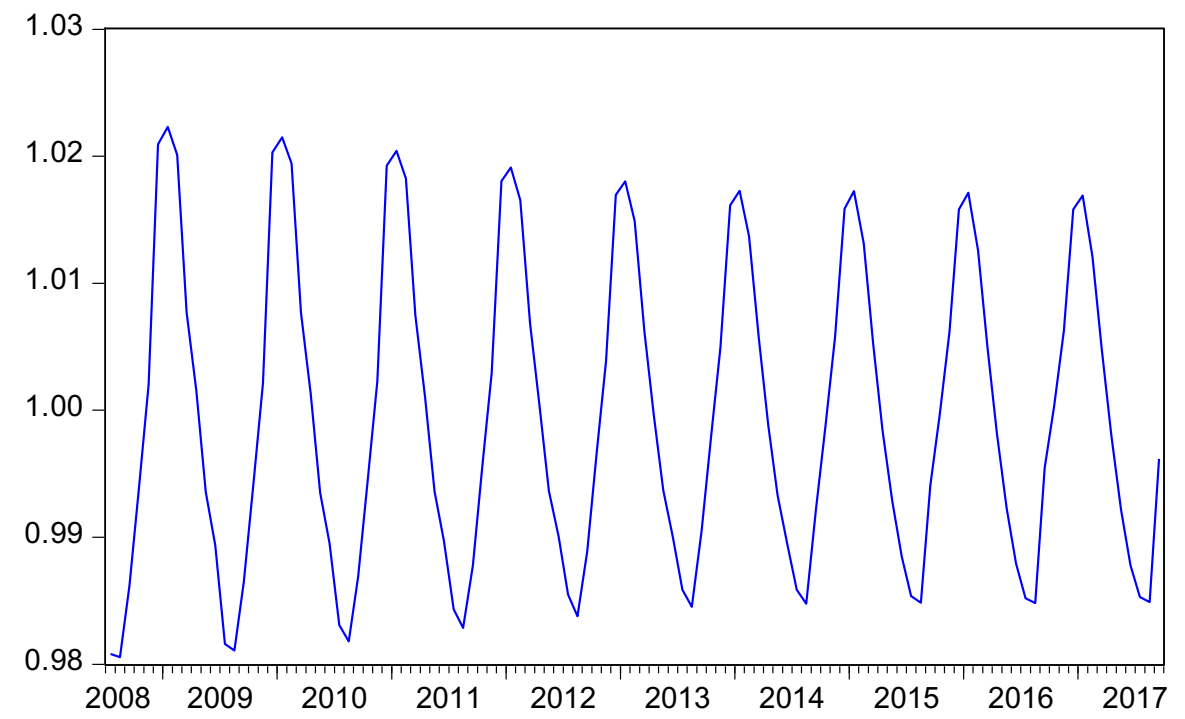

Figure 2. Seasonal Fluctuation of National Average Price of Raw Milk (monthly)

\section{Irregular factors}

Figure3 shows that there are irregular factors in raw milk price fluctuations besides regular ones. Irregular events are contingent and difficult to foresee. And we find the irregular volatility has been becoming stronger in the past years. 


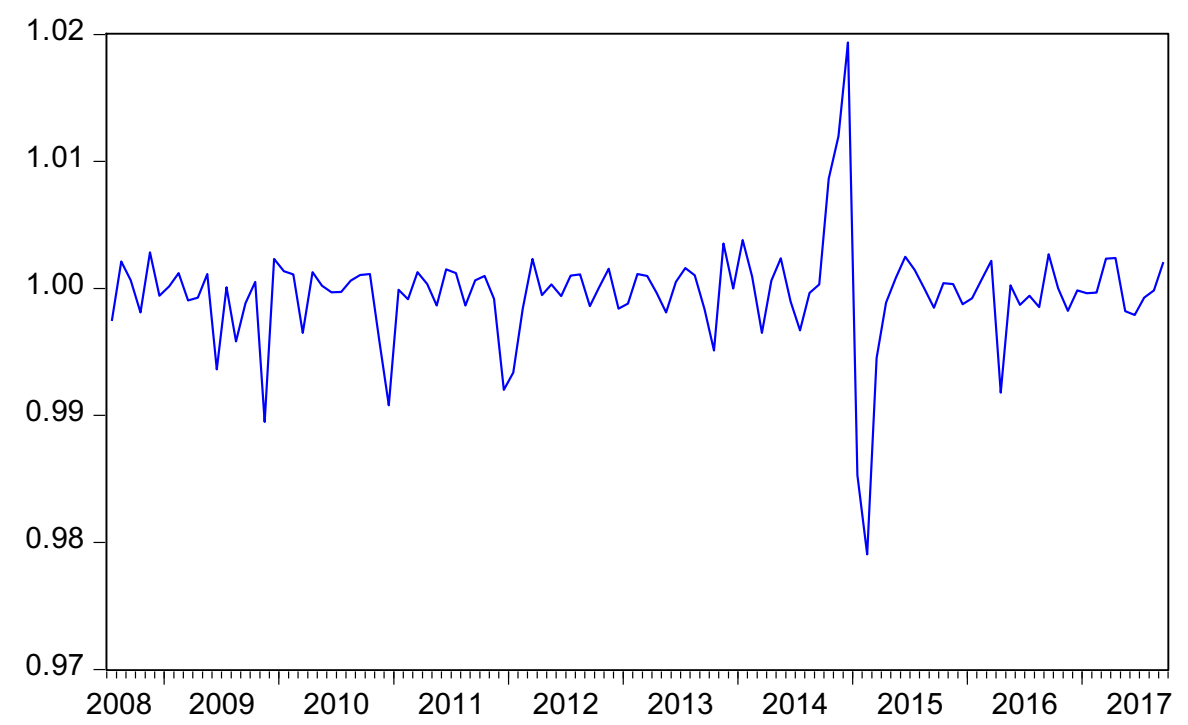

Figure 3. Irregular Fluctuation of National Average Price of Raw Milk (monthly)

\section{Feasibility Analysis and Foreign Experience \\ Feasibility of insuring price risk}

Insurable risks are risks that meet all the criteria for efficient insurance, which is the fundamental principle of designing any insurance product. To be an insurable risk, it should meet the following requirements: Firstly, the insurer must be able to measure the premium which can cover the claims and operating expenses, or to say it cannot be catastrophic or so large that nobody want to insure it. Secondly, the loss must be able to be measured by money. Thirdly, the happening of loss should be random. In other words, the risks need to be unforeseeable and the insured cannot exert influence on the happening of loss, or the insurers will get into trouble of adverse selection. Fourthly, the risks must be able to be spread from the points of space or time to maintain the sustainability of insurance operation [11].

However, we find there are significant cyclical and seasonal characteristics in raw milk price fluctuations, which means the price risk is not completely random. The potential problem of insuring it is a great possibility of adverse selection. Dairy producers will make expectations about the milk price in a future time using their experiences and historical information. They'll purchase insurance only when they expect the price would go down. This will increase insurers' operating risks, which may result in higher premium or quit concern. That will be a no-win situation or both sides. Meanwhile, price risks are strongly systematic, and could be only spread over time while couldn't in space, which is a seed of catastrophe events. Once serious incident happens, the indemnity responsibility could be destructive for the insurers.

But this doesn't mean that price risks can't be insured. By technical and institutional innovations, the impacts of uninsurable elements can be weaken. As for the ubiquitous problem of relatively high premium of agricultural insurance, the government could solve it by fiscal subsidies or other political support. Besides, by creatively designing insurance scheme, such as setting up stipulation on coverage level from aspects of production covered and risk retention, we can mostly avoid the happening of adverse selection. The government could collaborate with insurance companies in establishing catastrophic risks protection system and discussing the reasonable plan.

\section{Foreign Experiences}

There have been many related practices in oversea countries like United States and Canada. Most of them are in form of revenue insurance. Revenue insurance is a good risk management method for many agricultural products. Because supply, which is a key determinant of market 
price, is determined by production, then production and price usually move inversely. The insurance indicator of revenue insurance is the unit price multiplied by production. So it actually covered both natural and market risks. Revenue insurance products are more attractive to producers of main crops, which are under both natural and market risks, such as corn, soybean, and cotton and so on. But for livestock products, natural risks are comparatively light, and the main risks faced with production activities are from the market. Moreover, the productivity of livestock products are easily subject to human influence, which prone to induce moral hazards [9].

There are only 4 protection programs specialized for agricultural products price risks in practice. They are Livestock Risk Protection Program (LRP), Livestock Gross Margin Program (LGM) and Margin Protection Program for Dairy Producers (MPP) of United States, and the Western Price Insurance Program (WLPIP) of Canada. LRP and WLPIP are in similar form of taking product price as insurance indicator and paying the differences between the contracts agreed price and the actual price to the insured when the actual price is lower than the agreed. LGM is a protection program for the gross margin of swine and dairy milk, while MPP is only available for Dairy producers. The LGM-D and MPP are the same in using income over feed cost per hundred pounds (IOFC) as insurance indicator. But there are also many differences between them. Firstly, the feed ration coefficients of LGM-D can be adjusted by the producers within a certain interval to accommodate their individualized demands, while the coefficients of MPP are fixed according to the 2014 Farm Bill. Secondly, production and length to be covered in LGM-D are customizable, and indemnities are only paid when the average IOFC in the whole contract duration is less than the guaranteed value, while MPP requires a fixed historical productivity and only covers a certain proportion of it during the whole contract period, and the indemnities are calculated on every two-month basis. Thirdly, the guaranteed gross margin and premium in LGM-D are based on the future prices of milk and feed in the register period, and the insurance premiums are actuarially fair and calculated separately. While the guaranteed levels of MPP are fixed from $\$ 4$ to 8 per hundred pounds with the intervals of 50 cents, the premium for each guarantee is fixed too, not reflecting the changes of risk environment.

\section{SCHEME DESIGN OF RAW MILK PRICE INDEX INSURANCE}

There are four key points in designing the framework of raw milk price index program, one is the choice of insurance indicator, in other words the milk price index. The other one is the index construction. The third is to scientifically make contract clauses to avoid moral hazards and adverse selection. And the last one is calculation of insured amount and premium.

\section{Insurance Indicator}

Price index is the indicator used in raw milk price index insurance to measure dairy producers' gross margin and as the basis of indemnity payments. So the choice of milk price index is the core of the scheme design. There are mainly three alternatives of milk price index throughout the world, milk price (MP), milk-to-feed price ratio (MF) and the income over feed cost (IOFC). MP refers to the average price of per unit weight milk (like 1 kilograms, 50 kilograms or 100 pounds) received by the dairy producers in certain areas. The advantage of taking MP as insurance indicator is that it could be easy to design the contract and easy for farmers to understand, and the data used is easy to acquire. But there's still a serious defect that the milk price cannot truly reflect dairy producers' actual profitability. The price risks faced with dairy production are not only from the final products, but also the inputs. In short terms, the profitability may not decrease when the low milk price is caused by cost reduction, while the insured producers may could claim for payment for the decreased MP. However, when the cost 
substantially rises and the supply-demand balance adjustment moves slowly, the MP can't increase to the level of reasonable return, the insurance maybe can't pay enough for the margin losses, which will result in insurance inefficiency. So we need to involve the main measurable variable costs into consideration when constructing milk price index.

According to the "The Collection of Cost and Benefit of National Agricultural Products" published by China National Statistics Bureau, feed cost accounted for about $65 \%$ of the total cost of dairy cow raising and $80 \%$ of the material and service expenses in recent years. Feed price changing is an important reason for milk price fluctuation. Producers' profitability would be probably brought down by increasing feed prices. And feed costs are comparatively more region homogeneous and easier to measure than labor and land cost. Therefore, the existing foreign milk price index insurance programs all put feed cost into the price index as representative of production cost, and the main forms are MF and IOFC.

United States Department of Agriculture has always taken MF as proxy for milk production profitability. It's defined as the all-milk price per hundredweight (in dollars) divided by a feed price index, which is the cost of 100 pounds of a representative feed ration. It's similar with the ratios used in some other livestock sectors, such as swine-corn price ratio and broiler-corn ratio [20]. This product-feed price ratios can easily and quickly reduce the impact of feed price changes on milk price, especially when only one factor of milk and feed price in great variation. But when milk and feed price both fluctuate and in the same direction, the MF may change little, while the margin received by producers can be totally different. For example, when the $\mathrm{MF}$ is 2.5 and the milk price is $150 \mathrm{RMB} / 50 \mathrm{~kg}$, the implied feed cost and gross margin are $60 \mathrm{RMB}$ and $90 \mathrm{RMB}$. However, when the milk price is $100 \mathrm{RMB} / 50 \mathrm{~kg}$ and MF doesn't change, the margin decreases to only 60RMB.

We think IOFC could be a better indicator for our raw milk price index insurance scheme. First of all, it can better reflect dairy producers' real profitability by taking feed cost into account, which is in line with the objective of developing milk price insurance. Secondly, as a representative of gross margin, IOFC, to some extent, can be a reflection of farmers' expectation on future profitability. Finally, for IOFC is determined by several prices, it's more random than the single milk price, which is helpful to avoid adverse selection. Taking IOFC as the insurance indicator, the insured and insurer need to set a reasonable guarantee level in the insurance contract. When the actual IOFC calculated using statistic data in the prescribed area falls below the guarantee level in the insurance period, the difference between them shall be paid to the insured dairy producers.

\section{Price Index Construction}

The milk price index we constructed is as the follow:

$$
\text { PIn }=P_{m}-\sum Q_{i} P_{i}
$$

We take $50 \mathrm{~kg}$ as milk production unit in price index calculation. In the above formula, "PIn" refers to raw milk price index, IOFC. " $P_{m}$ " is the raw milk price per $50 \mathrm{~kg}$ received by producers (in RMB). " $Q_{i}$ " is the quantity of feed "i" consumed for $50 \mathrm{~kg}$ milk production (in kilograms), and $P_{i}$ is the price per kilograms of feed "i" (in RMB).

Before the index construction, we should know the general feed ration of dairy cow raising in China. The feed for cow herds are composed of concentrated feed and coarse fodder. Concentrated feed mainly includes corn, oil-seed-meal and soybean, and coarse fodder consists of silage, alfalfa hay, green grass and residual forage. Among these, corn, oil-seed-meal, silage 
corn and alfalfa hay are respectively the main concentrated and coarse feed, which account for $75 \%$ and $70 \% \sim 80 \%$ of the two kinds of feed. For the strong substitution and price relevance among different oil-seed-meals, we take soybean meal, which is the most widely used in cow raising, as representative. Silage corn price usually change in the same direction with corn price and significantly influenced by it. So we can covert silage corn into corn at a certain ratio. Then the feed ration of dairy cow raising could be represented by corn, soybean meal and alfalfa hay.

With the data published by China Ministry of Agriculture and other public information, we can calculate the coefficients of each feed in the index. The data used here is national data of 2015. The calculating process is as follows:

$1 \mathrm{~kg}$ milk called for $0.5316 \mathrm{~kg}$ concentrated feed. Considering the most typical concentrated feed ration of $50 \%$ corn and $25 \%$ soybean meal, the corn and soybean meal consumption for $1 \mathrm{~kg}$ milk production were $0.2658 \mathrm{~kg}$ and $0.1329 \mathrm{~kg}$. The silage corn consumption for each production of $1 \mathrm{~kg}$ milk was $1.0927 \mathrm{~kg}$. As silage corn price is highly correlated with corn, we convert it into corn using their price ratio 0.1495 as conversion factor. As for alfalfa hay, the feed consumption for $1 \mathrm{~kg}$ milk production was $0.0799 \mathrm{~kg}$, in which $60 \%$ was domestic production and the other $40 \%$ was imported. The acceptable price of domestic alfalfa hay price for dairy cow raising is considered to be $70 \%$ of the imported. So the domestic price can be expressed as imported alfalfa hay price multiplied 0.7. Therefore the alfalfa hay price in the index can be calculated by the following formula: $\mathrm{P}_{a l}=0.6 P_{a l f}+0.4 \times 0.7 P_{a l f}=0.88 P_{a l f}$. $\mathrm{P}_{a l}$ refers to the alfalfa hay price that we use in the milk price index, and $P_{\text {alf }}$ is the price of imported alfalfa hay (in RMB).

Then, the integrated milk price index is:

$$
\text { PIn }=P_{m}-21.46 P_{c}-6.645 P_{s}-3.515 P_{a l f}
$$

$P_{c}$ and $P_{S}$ represent per kilograms price of corn and soybean meal. Limited by data availability, the data used in milk price index construction are all national data. Milk price and corn price are respectively the monthly average raw milk and corn prices calculated with the weekly or daily prices of ten main milk production provinces that published by China Ministry of Agriculture (CMOA). Soybean meal price is the monthly average price of national spot prices published by CMOA. The imported alfalfa hay price is the monthly average CIF price in RMB that published by China General Administration of Customs.

\section{Moral Hazards and Adverse Selection}

We have known that there are foreseeable cyclical and seasonal factors in raw milk price fluctuations in China, which may result in serious moral hazards and adverse selection. Appropriately solve these problems is the greatest challenge of underwriting milk price risks.

Traditional insurance products generally pay for the indemnities based on individual losses. Dairy farmers under insurance protections are likely to relax the management or reduce the input, which may result in production decrease or quality decline. Then the price or margin they receive may be less than the guarantee level, and the claims will happen. And this can be called moral hazard. It's not easy for insurers to recognized and control these risks for sake of information asymmetry. The operating cost will be very high. Taking "price index", on which individual produces can't exert influence, as the basis of measuring losses can effectively reduce the occurrence of moral hazards. But when the program is conducted in small scale, the local operations may still be powerful to affect the whole market. To solve this problem, we can 
use data of upper level region or neighbor area in guarantee and actual price index value calculation. For example, the program piloted in Baoding City can use the data of Hebei Province or the neighbor province Shandong or Liaoning. Another measure to cope with moral hazard is to set up rational coverage percentages and let producers take some of the risk by themselves. This is an experience from MPP of United States, in which dairy farmers can choose a fixed coverage percentage of historical productivity and keep at least $10 \%$ risks uninsured.

After measurement, we find the milk price index we set also has cyclical and seasonal moving characteristics. When dairy producers can freely decide when to purchase insurance and how much production to cover, the existence of foreseeable factors may give producers chances to purchasing for large amount of milk under low margin expectation, and purchase little in the opposite case. Serious adverse selection may make the insurance program unsustainable. It relies on scientific design of the contract to eliminate adverse selection. Firstly, the coverage period should be long enough. When it is as long as the length of cyclical fluctuation, the former foreseeable periodic and seasonal factors will become insignificant [12]. We divide the calculated milk price index from 2010 to now into three moving cycles. The lengths of them are 33 months, 24months and 8 months. This implies that the cyclical fluctuation frequency is accelerating, and the cycle length is becoming shorter and difficult to foresee. So the cyclical factors are not that important in the scheme design. In consideration of the significant seasonal fluctuation, the coverage period can be set for 12 months. And the indemnity payments are evaluated on a 12-monthly basis. Secondly, there should be a limitation on the production to cover. For purchasing the insurance, the producers should provide real proof of the historical productivity and determine a fixed coverage level, which is a proportion of the whole productivity. For example if the selected coverage level is $90 \%$ for an operation whose annual production is 1000 tons, the insured quantity of milk is 900 tons. To avoid the happening of adverse selection, the producers in such price index insurance programs will not be allowed to greatly adjust the coverage level within certain years. For the operations are likely to adjust the size of herds and the yield per cow will increase with improving raising techniques, the program can set a production adjustment mechanism. When the production capacity changes, producers can apply for a new insured quantity with supporting evidence for the new productivity under comparatively constant coverage level.

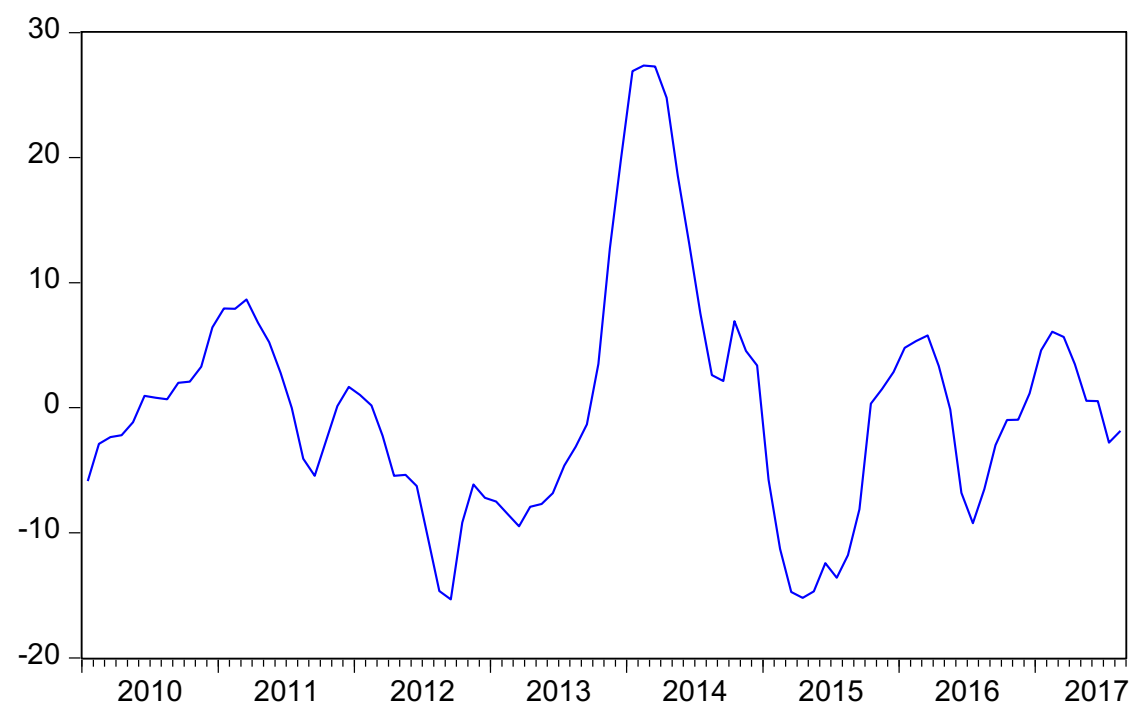

Figure 4. Cyclical Fluctuations of Milk Price Index 


\section{Insurance Amount and Premium Calculation}

\section{Insurance amount}

According to the above settings, the insurance amount of a raw milk price index insurance policy can be calculated using this following formula:

$$
\operatorname{In} A=\operatorname{PIn} \cdot \beta Q
$$

InA represents insurance amount of an insurance policy. PIn is the guaranteed price index value written in the contract. $\beta$ is the coverage level of the total productivity $Q$.

When the average PIn during the insurance period falls under the guaranteed level, the difference between them will be paid. The indemnity is:

$$
\text { Ind }=(P I n-A P I n) \cdot \beta Q
$$

APIn refers to the actual average milk price index during the insured period. The data sources used in the calculation can be selected according to practical needs.

\section{Premium calculation}

In general practice, loss distribution is the basis of premium determination. Loss distribution in the future is assumed to be the same as the history, and be used to estimate the future expected losses. The present discounted values of these expected losses are that we call pure premium. But this method requires large amount of historical data, while we can only access useful related data of about 10 years.

The raw milk price index insurance we designed above is actually a kind of Asian options portfolio, which involves a put option of dairy milk and call options of feed. It's very difficult to price for such kind of products, because the prices we use in index construction are average values, which have no closed form distributions, not to mention the sum of them.

In view of the foreign experiences, distribution approximation and Monte Carlo simulations are performed. We here use these method as references to determine the actuarially fair premium for our designed raw milk price index insurance.

Researches by Turnbull and Wakeman (1991) and Levy (1992) show that the use of a lognormal distribution is a good approximation [15]. So, in this study, all the prices in the price index are assumed to follow lognormal distributions, which are defined by reasonable estimations of the means and standard deviations of prices. Then we calculate the premium using a Monte Carlo simulation procedure. Inputs into the simulation are monthly milk, corn, soybean meal and alfalfa hay prices draws. Every set of random "draws" includes 12 groups of monthly prices of milk and the feed. Each group of prices can determine a monthly milk price index. And the average of the 12 index value within one set is one annual simulated index value (ASIV). So the expected loss is the difference between ASIV and guaranteed level when ASIV is smaller, or 0 otherwise. Repeat these procedures for 10000 times, then the average of expected losses can be taken as the pure premium. The calculation steps are as the follows:

$$
\operatorname{SPIn}(i, m)=P_{m}(i, m)-21.46 P_{c}(i, m)-6.645 P_{s}(i, m)-3.515 P_{a l f}(i, m)
$$




$$
\begin{gathered}
\operatorname{SPIn}(i)=\frac{1}{12} \sum_{m=1}^{12} \operatorname{SPIn}(i, m) \\
\operatorname{Loss}(i)=\max (G P \operatorname{In}-\operatorname{SPIn}(i), 0) \\
\operatorname{Premium}=\frac{1}{10000} \sum_{i=1}^{10000} \operatorname{Loss}(i)
\end{gathered}
$$

$\operatorname{SPIn}(i, m)$ refers to the simulated price index $i$ for month $m . P_{m}(i, m), P_{c}(i, m), P_{s}(i, m)$ and $P_{\text {alf }}(i, m)$ are respectively the simulated per $50 \mathrm{~kg}$ milk and per kg corn, soybean and imported alfalfa hay prices $i$ for month $m$. Loss $(i)$ is the simulated indemnity payment in simulation $i$, and GPIn is the price index guarantee for the insurance period.

According to this method, we take the last milk price fluctuation cycle (from April, 2014) as basis, and take the means and standard deviations of national raw milk price, corn price of main milk production provinces, national soybean meal price and imported CIF alfalfa hay price in this period as parameters to define the lognormal distributions of prices. The actuarially fair premiums we calculate are in Table1.

Table1. Pure Premium and Premium rate of Different Guarantee

\begin{tabular}{|c|c|c|c|c|c|c|}
\hline $\begin{array}{c}\text { Guarantee } \\
\text { (RMB) }\end{array}$ & 105 & 106 & 107 & 108 & 109 & 110 \\
\hline Premium (RMB) & 0.49 & 0.75 & 1.11 & 1.59 & 2.15 & 2.76 \\
\hline Premium rate & $0.47 \%$ & $0.70 \%$ & $1.04 \%$ & $1.47 \%$ & $1.97 \%$ & $2.51 \%$ \\
\hline
\end{tabular}

\section{CONCLUSIONS}

On the base of analyzing the fluctuation characteristics of raw milk price in China, we analyzed the feasibility of insuring raw milk price risk. And we designed an insurance scheme from aspects of choice and construction of insurance indicator, moral hazards and adverse selection elimination, calculation of insurance amount and premium. We can get some conclusion from this study.

1) There are trend and cycle, seasonal factors and irregular factors in China raw milk price fluctuations. Trend, cyclical and seasonal movements of the price to some extent are foreseeable for seasoned dairy producers, while the irregular factors caused by unexpected and uncontrollable accidents are difficult to foresee.

2) For the existence of foreseeable factors and systematicness, raw milk price risk is not completely insurable. The impacts of uninsurable factors can be eliminated by technical and institutional innovations, such as government subsidy and scientific scheme design.

3) The selection of insurance indicator is the core of raw milk price index insurance design. Compared with milk price and milk-to-feed price ratio, income over feed cost can better reflect the real profitability of milk production and producers' margin expectation, and is more random.

4) Moral hazards and adverse selection are the most serious challenges we face in the insurance scheme design. The negative impacts can be eliminated by flexible selection of data sources, limiting coverage levels, reasonable insurance period.

\section{References}

Bozic, Marin, et al. "Margin Protection Program for Dairy Producers: Implementation, Participation and 
Consequences."Selected Paper prepared the AAEA Crop Insurance Symposium, Louisville, KY. 2014.

Cabrera, V.E., and D. Solis. 2008. Managing the newly created LGM-Dairy insurance under seasonal climate variability. J. Dairy Sci. 91 (Suppl. 1):557.

Cabrera, Victor E., B. W. Gould, and M. Valvekar. "Livestock Gross Margin Insurance for Dairy Cattle: An Analysis of Program Performance and Cost under Alternative Policy Configurations." General Information(2009).

Chuhui, L., Yan, W. " Study on the Impact of Agricultural Products Price Insurance on the Market and the Fisical Policies: the Case of Shanghai Vegetable Price Insurance Program." Public Finance Studies 11(2012):16-19.

Farm Bureau. 2018 Farm Bill. What are the differences between MPP and LGM-Dairy? https://www.fb.org/files/2018FarmBill/What are the Differences between MPP and LGM-Dairy.pdf

Gould, B., and V. Cabrera. "USDA's Livestock Gross Margin Insurance for Dairy: What is it and how can it be used for Risk Management." Staff Paper 562 (2011).

Guodong, J., Ke, W. "Study on Farm Produce Price Index Insurance." Southwest Finance 8(2016): 72-76.

Hui, T. "The Difficulties and Principles in developing Farm Produce Price Insurance in China." Economic Review 6 (2016): 62-69.

Ke, W., et al. "The Feasibility of Farm Produce Price Index Insurance." Insurance Studies 1(2014): 40-45.

Mark, Tyler, and Kenneth Burdine. "Will the New Dairy Margin Protection Program Reduce Risk for Dairies?." Selected Paper prepared for presentation at the Southern Agricultural Economics Association's 2015 Annual Meeting, Atlanta, Georgia. 2015.

Qixiang, S. "Insurable risks: the foundation of insurance". China Insurance (2009): 12-16.

Qiao, Z., Biwang, W., Ke, W. "The Feasibility and Scheme Design of Swine Price Insurance in China." Insurance Studies 1(2015):54-

Qiao, Z., Biwang, W., Shuting, S., "Study on Price Insurance of Eggs in Beijing." Agricultural Outlook 9.11(2013):4650 .

Risk Management Agency (RMA). 2009c. Livestock gross margin insurance policy: Step by step instructions to calculate premium. USDA Risk Management Agency.

Risk Management Agency (RMA). 2009a. Livestock gross margin insurance policy. http://www.rma.usda.gov/policies/20

Si, C., Guixia, Qian. "Raw Milk Price Fluctuation and the Control Policies." Agricultural Outlook 7.6 (2011): $15-18$.

Stephenson, Mark W., and Andrew M. Novakovic. "The dairy subtitle of the Agricultural Act of 2014." Choices 29.1 (2014): 1-4.10/lgm/10lgmdairypolicy.pdf Accessed Aug.14, 2009.

Valvekar, Mayuri, et al. "Revenue risk management, risk aversion and the use of Livestock Gross Margin for Dairy Cattle insurance." Agricultural Systems 104.9(2011):671-678.

Valvekar, M., V. E. Cabrera, and B. W. Gould. "Identifying cost-minimizing strategies for guaranteeing target dairy income over feed cost via use of the Livestock Gross Margin dairy insurance program." Journal of Dairy Science 93.7(2010):3350-7.

Wolf, C. A. "Understanding the milk-to-feed price ratio as a proxy for dairy farm profitability." Journal of Dairy Science 93.10(2010):4942-8.

Wolf, C. A. "Dairy farmer use of price risk management tools. " Journal of Dairy Science 95.7 (2012):4176-4183. 